\title{
Global assistance in caring for Syrian refugees
}

Mujalli Mhailan Murshidi

Keywords: Syrian refugees, Neonates

\section{Main text}

In 2013, while I was the Minister of Health and Minister of Environment in Jordan, the majority of the neonates at neonate unit at the Mafraq Maternity and Neonate Hospital in northern Jordan were borne to Syrian women (Syrian refugees needed up to 18 of the 20 beds most of the time during that year). This makes me agree with the work of Fuat Emre Canpolat et al. which concluded that further research is needed to understand the relative morbidity of babies born to Syrian refugees compared to the local population, as well as the economic impact on facilities treating these cases [1]. Jordan is committed to the health of both Syrians and Jordanians. However, the health system is dangerously overstretched. Excessive demands on the health system pose risks to the health status and social stability. The international community is invited to better assist in the efforts to fulfil these demands [2].

A recent editorial in The Lancet stated clearly that the WHO's European Health Report 2015 lacks attention, and strikingly so, to preparedness and provision for the health of refugees and migrants [3]. The ongoing largescale movement of people escaping conflict in Syria and other countries has had a dramatic effect on several European region states, with two million or more people having entered Turkey and migration to other European countries ongoing. It is, at the very least, disappointing that a flagship WHO Europe health report should overlook such a major challenge to comprehensive and equitable health provision in the region. The next report should be holistic in specifically addressing planning and provision for migrants' health in all of the region's affected countries [3]. Finally, it should be stressed that WHO and UN Organizations reports bring attention to

preparedness and the provision of health care for refugees and migrants, in Europe, Jordan and in other areas affected by this regional crisis, for better planning and active support.

\section{Ethics approval and consent to participants}

Not applicable.

\section{Consent for publication}

Not applicable.

\section{Availability of data and material}

Available.

Competing interests

The author declares that he has no competing interests.

Acknowledgements

None.

Funding

None.

Received: 4 February 2016 Accepted: 23 February 2016

Published online: 23 March 2016

\section{References}

1. Büyüktiryaki M, Canpolat FE, Alyamaç Dizdar E, Okur N, Kadıoğlu Şimşek G. Neonatal outcomes of Syrian refugees delivered in a tertiary hospital in Ankara, Turkey. Confl Health. 2015:9:38. doi:10.1186/s13031-015-0066-1.

2. Murshidi MM, Hijjawi MQ, Jeriesat S, Eltom A. His Excellency. Lancet. 2013; 382(9888):206-7.

3. Europe in 2015-health in a diverse and changing region. Lancet. 2015; 386(10000):1211. doi: 10.1016/S0140-6736(15)00311-6.

Correspondence: mujalli_mhailan@hotmail.com

University of Jordan, Amman, Jordan

(c) 2016 Murshidi. Open Access This article is distributed under the terms of the Creative Commons Attribution 4.0 International License (http:/creativecommons.org/licenses/by/40/, which permits unrestricted use, distribution, and reproduction in any medium, provided you give appropriate credit to the original author(s) and the source, provide a link to the Creative Commons license, and indicate if changes were made. The Creative Commons Public Domain Dedication waiver (http://creativecommons.org/publicdomain/zero/1.0/) applies to the data made available in this article, unless otherwise stated. 